05

\title{
Теплоперенос в формировании термоупругого и термоэлектрического отклика металлов на воздействие лазерного импульса
}

\author{
(C) Б.А. Зимин, ${ }^{1}$ Ю.В. Судьенков ${ }^{2,3}$ \\ ${ }^{1}$ Балтийский государственный технический университет „Военмех“, \\ Санкт-Петербург, Россия \\ ${ }^{2}$ Санкт-Петербургский государственный университет, \\ Санкт-Петербург, Россия \\ ${ }^{3}$ Институт проблем Машиноведения РАН, \\ 199178 Санкт-Петербург, Россия \\ e-mail: y.sudenkov@yandex.ru \\ Поступило в Редакцию 23 июля 2018 г. \\ В окончательной редакции 23 июля 2018 г. \\ Принято к публикации 15 апреля 2019 г.
}

\begin{abstract}
Представлен анализ влияния процесса теплопереноса в металлах на параметры термоупругого и термоэлектрического отклика металлов на импульсное лазерное воздействие. Показано, что двухстадийный анализ динамической задачи термоупругости и термоэлектрического эффекта позволяет получить адекватное описание результатов экспериментов. Представленные результаты продемонстрировали значительную зависимость параметров отклика от микроструктуры, что указывает на возможность разработки высокоэффективного метода неразрушающего контроля качества металлов.
\end{abstract}

Ключевые слова: термоупругость, термоэлектричество, лазерное воздействие, неразрушающий контроль.

DOI: 10.21883/JTF.2019.12.48481.292-18

\section{Введение}

К настоящему времени имеется большое число работ, посвященных разработке обобщенных моделей процесса теплопереноса в металлах, учитывающих различие электронной и ионной температур и инерцию теплообмена между ними [1-3]. Также представлено достаточно большое количество работ, посвященных описанию термоупругого эффекта с учетом таких моделей $[4,5]$. Имеется большой объем исследований, направленных на изучение термоЭДС в металлах, в частности, для возможности использования этого явления для диагностики их структуры $[6,7]$.

Однако внимания проблеме взаимосвязанности двух эффектов, обусловленной процессом теплопереноса, практически не уделялось. При этом влияние микроструктуры на теплопроводность и электропроводность металлов, как известно, весьма существенно [8,9] и по всей видимости должно сказываться на параметрах и термоупругого, и термоэлектрического отклика металлов на импульсное лазерное воздействие.

В работах [10-12] было показано принципиальное различие параметров импульсов термонапряжений, возбуждаемых в металлах и диэлектриках при импульсном лазерном воздействии. Существенные различия появляются после окончания действия импульса лазера и обусловлены тем, что в диэлектриках наведенный излучением тепловой источник практически локализован в области поглощения излучения, тогда как в металлах достаточно эффективный процесс теплопереноса опре- деляет дальнейшее формирование термонапряжений в среде.

Типичные формы импульсов термонапряжений в диэлектрике (цветное стекло СЗС-22) и металле (алюминиевый сплав Д16) представлены на рис. 1. Видно, что основные различия наблюдаются в металлах на стадии процесса теплопереноса, формирующим фазу растяжения после окончания импульса лазера. Этот эффект определяется отличием механизмов теплопере-

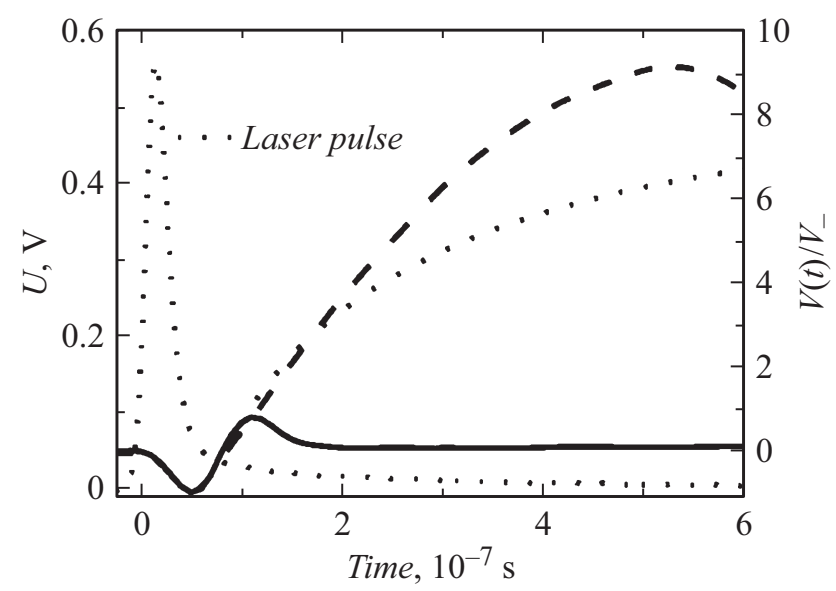

Рис. 1. Лазерный импульс и типичные формы импульсов термонапряжений в диэлектрике (цветное стекло СЗС-22 - сплошная кривая), в металле (алюминиевый сплав Д16 - штриховая кривая) и расчет с учетом (2) - пунктирная кривая. 
носа - фононный в диэлектриках и электронный в металлах $[13,14]$. Поэтому взаимосвязь термоупругого и термоэлектрического процессов в металлах представляется очевидной.

В работах по исследованию термоупругого эффекта в металлах при лазерном воздействии $[15,16]$ была показана взаимосвязь термоупругих и термоэлектрических процессов. Целью данных исследований являлось более глубокое изучение такой взаимосвязи, а также влияния микроструктуры на параметры этих процессов при импульсном лазерном воздействии.

\section{Анализ}

Как было показано в ряде работ [17-19], форма импульсов термонапряжений в диэлектриках достаточно хорошо описывается в рамках классической постановки динамической задачи термоупругости, т.е. для случая локализации теплового источника излучения в зоне поглощения и практически отсутствующего теплопереноса. Однако для металлов решение в рамках такого подхода не соответствует результатам экспериментов (рис. 1).

В работах $[16,20]$ были представлены варианты двухстадийного анализа динамической задачи термоупругости при импульсном лазерном воздействии на металлы. Было показано, что на первой стадии, определяемой действием импульса излучения $\left(t \leq \tau_{L}\right)$, можно использовать решение классической задачи, так как влияние процесса теплопереноса незначительно при длительностях лазерного воздействия $\tau_{L}<10^{-(7-8)} \mathrm{s}$.

На второй стадии после окончания действия импульса излучения $\left(t>\tau_{L}\right)$ формирование механических напряжений в металлах целиком определяется динамикой процесса теплопереноса и не описывается в рамках классической динамической задачи термоупругости.

В работе [20] представлена приближенная модель формирования напряжений растяжения в металлах на второй стадии и получена зависимость для массовой скорости частиц $v_{T}$ в заданном сечении $z_{i}$ :

$$
v_{T}\left(z_{i}, t\right)=c_{0}^{2} \alpha_{T} \int_{\tau_{L}}^{t} \frac{\partial T}{\partial z} d \tau .
$$

С учетом решения теплового уравнения получим

$$
\begin{aligned}
v_{T}\left(z_{i}, t\right)= & -c_{0}^{2} \alpha_{T} \frac{q_{0}}{k} \int\left[\operatorname{erfc}\left(\frac{z_{i}}{2 \sqrt{\chi t}}\right)\right. \\
& \left.-\operatorname{erfc}\left(\frac{z_{i}}{2 \sqrt{\chi\left(t-\tau_{L}\right)}}\right)\right] d t,
\end{aligned}
$$

где $c_{0}$ - объемная скорость звука, $\alpha_{t}-$ коэффициент теплового расширения, $q_{0}-$ поток излучения, $k-$ теплопроводность, $\chi-$ температуропроводность.

Суммируя эти решения, с учетом скорости теплопереноса получим зависимость, достаточно хорошо описывающую параметры фазы растяжения в металлах на стадии теплопереноса. Рассчитанная таким образом зависимость приведена на рис. 1.

Как следует из соотношения (2), параметры фазы растяжения, помимо интенсивности импульса излучения, зависят от упругих и тепловых свойств металлов, на которые значительное влияние может оказывать микроструктура.

Для оценки характера термоэлектрического отклика металлов и возможного влияния микроструктуры необходим дополнительный анализ электронного механизма теплопереноса в металлах на разных стадиях процесса - стадии действия импульса излучения и стадии теплопереноса из области поглощения излучения.

В течение воздействия импульса излучения на металлы в области поглощения одновременно протекают процессы, инициируемые электрическим полем с напряженностью, пропорциональной интенсивности импульса излучения, а также и градиентом температуры, возникающим в процессе термализации области поглощения с характерным временем порядка $10^{-10} \mathrm{~s}[21,22]$. В среде возникает электрический ток и тепловой поток, описываемые феноменологическими уравнениями [14,23]:

$$
\bar{j}=\hat{\sigma} \bar{E}+\hat{\beta} \overline{\nabla T}, \quad \bar{q}=\hat{\gamma} \bar{E}+\hat{\zeta} \overline{\nabla T},
$$

где $\hat{\sigma}, \hat{\beta}, \hat{\gamma}, \hat{\zeta}$ - кинетические коэффициенты Онзагера.

На первой стадии $\left(t \leq \tau_{L}\right)$ изменение тока для прямоугольного импульса излучения можно приближенно записать в виде [24]

$$
j_{1} \approx A_{1} \hat{\sigma} t-A_{2} Q \nabla T,
$$

где $Q$ - коэффициент Зеебека, $A_{1}$ и $A_{2}$ - коэффициенты пропорциональности.

Вторая стадия процесса $\left(t>\tau_{L}\right)$ обусловлена процессом теплопереноса газом почти свободных электронов и длится до установления теплового равновесия в среде. При этом напряженность электромагнитной волны уже отсутствует, но появляется напряженность $E_{2}=A \nabla T$, обусловленная градиентом температуры от наведенного излучением теплового источника.

Для одномерного движения электронов в случае малости возмущение плотности заряда и перемещении заряда, плотность тока на второй стадии $j_{2}$ можно записать в виде [8]

$$
j_{2} \approx e n_{0} V
$$

где $e-$ заряд электрона, $n_{0}-$ плотность электронов, $V$ - дрейфовая скорость электронов.

Уравнение движения электрона в электрическом поле с учетом потерь при столкновениях запишется в виде [9]

$$
\frac{d V}{d t}=\frac{e}{m_{e}} E_{2}-v V
$$

где $m_{e}$ - масса электрона, $v-$ эффективный коэффициент трения, характеризующий влияние микроструктуры на процессы электро- и теплопроводности. 

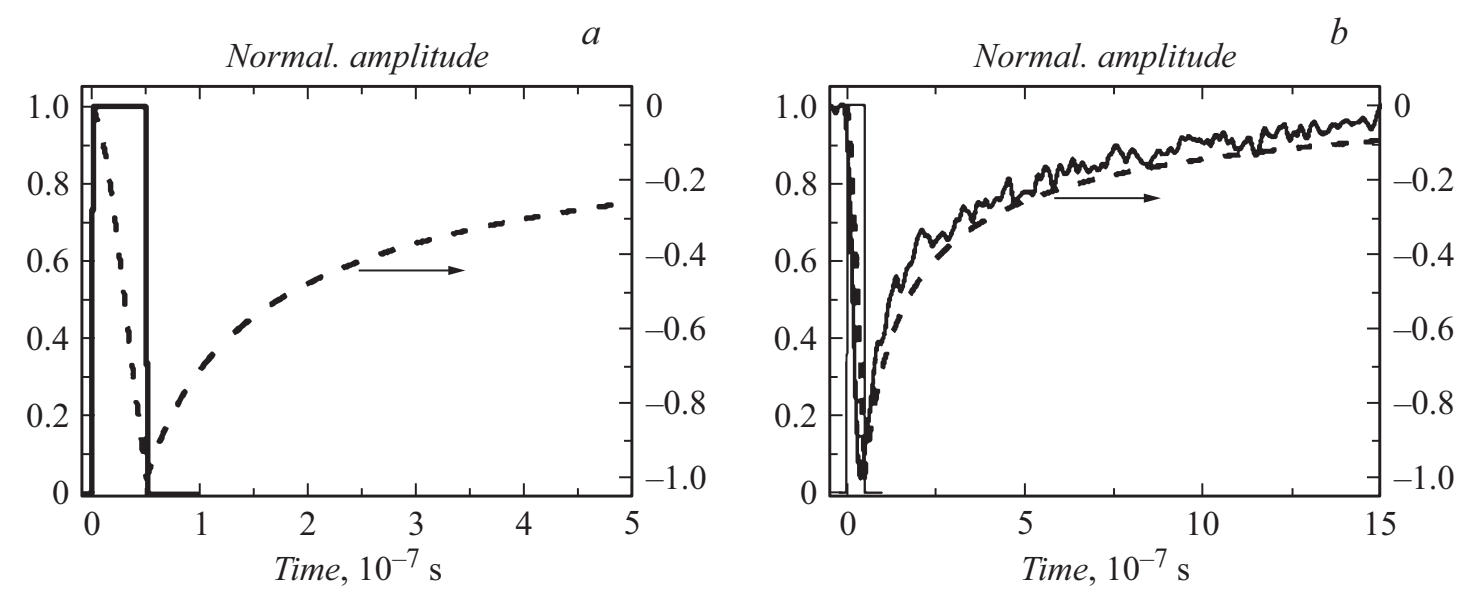

Рис. 2. $a$ - расчет термоэлектрического импульса по соотношению (9) (штриховая кривая); $b-$ сравнение расчетной (штриховая кривая) и экспериментальной зависимостей.

$a$

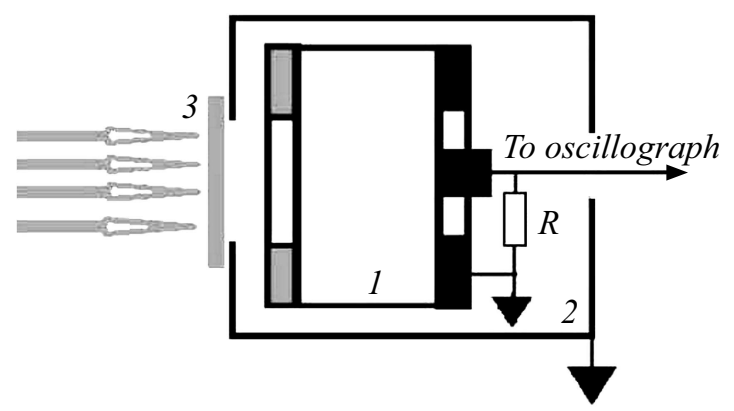

$b$

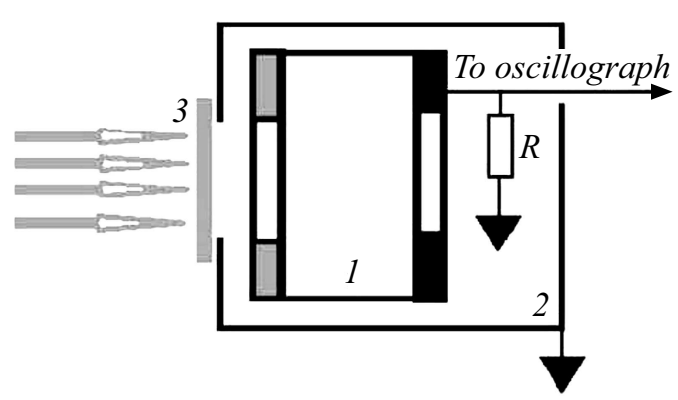

Рис. 3. Блок-схемы экспериментов для измерений термоупругого $(a)$ и термоэлектрического $(b)$ откликов: $1-$ образец, $2-$ экран, 3 - диффузное стекло.

С учетом (5) и (6) получим

$$
\frac{\partial j_{2}}{\partial t}+V \frac{\partial j_{2}}{\partial z}+v j_{2}=\frac{\omega_{p}^{2}}{4 \pi} E_{2}
$$

где $\omega_{p}^{2}=\frac{4 \pi e^{2} n_{0}}{m_{e}}-$ плазменная частота.

Полагая, что величина возмущения скорости электронов $V$ на длине свободного пробега мала $\left(V \frac{\partial j_{2}}{\partial z} \approx 0\right)$, получим

$$
\frac{\partial j_{2}}{\partial t}+v j_{2}=-\frac{\omega_{p}^{2}}{4 \pi} Q \nabla T_{2} .
$$

Применение данной модели описания термоэлектрического процесса на стадии теплопереноса $\left(t>\tau_{L}\right)$ позволяет сократить число параметров при описании, по сути, квантового объекта анализа, и оправдано при низкоэнергетическом возмущении газа свободных электронов.

Решение уравнения (8) для второй стадии процесса

$$
j_{2}=j_{1}\left(\tau_{L}\right)-\exp (-v t) \int_{\tau_{L}}^{t} \frac{\omega_{p}^{2}}{4 \pi} Q \nabla T_{2}(t) \exp (v t) d t .
$$

Как видно, характер решения для тока такой же, как и для массовой скорости частиц на стадии теплопереноса (2), Изменение напряжения и электрического тока пропорциональны интегралу от градиента температуры.

Результат вычислений тока для прямоугольного импульса излучения по соотношению (8) с учетом (4) приведен на рис. 2, $a$. На рис. 2, $b$ приведено сравнение расчетной и экспериментальной зависимостей тока от времени в медном образце при воздействии импульса лазера. Как видно, совпадение расчетной и экспериментальной зависимостей более чем удовлетворительное.

Блок-схемы экспериментальных исследований термоупругого и термоэлектрического откликов металлов и влияния микростуктуры на их параметры при импульсном лазерном воздействии представлены на рис. 3 .

Воздействие осуществлялось импульсным лазером с длиной волны $\lambda=1.06 \mu \mathrm{m}$, длительностью импульса излучения $\tau_{L} \approx 10^{-8} \mathrm{~s}$ и плотностью энергии порядка $10^{-2} \mathrm{~J} / \mathrm{cm}^{2}$. Диаметр области облучения равнялся $15 \mathrm{~mm}$.

Упругие импульсы регистрировались пьезокерамическим датчиком, нагруженным на сопротивление $50 \Omega$, с временным разрешением порядка $10^{-9} \mathrm{~s}$. Термоэлек- 

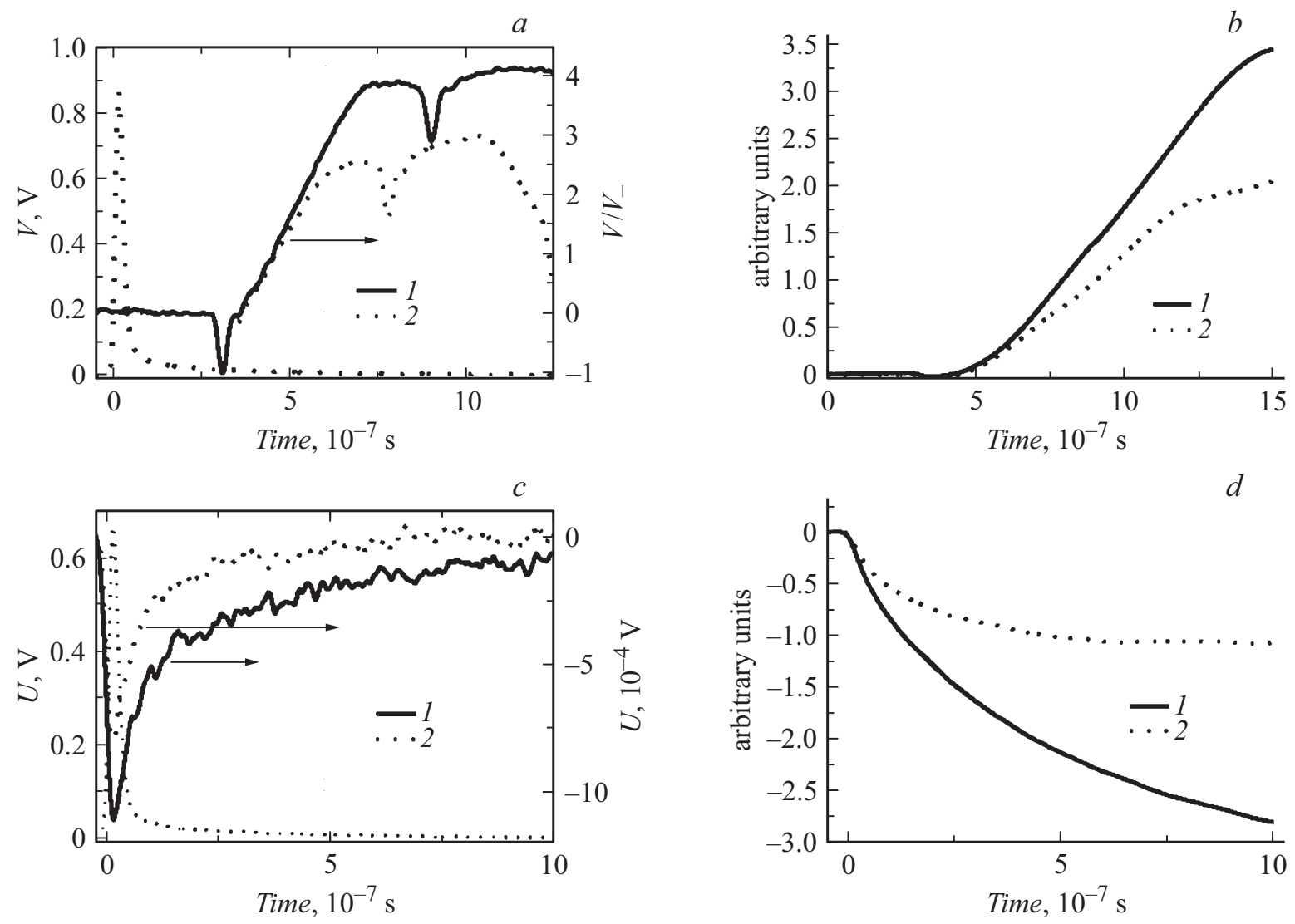

Рис. 4. $a-$ осциллограмма термоупругого отклика медных образцов М1 (пунктир - импульс излучения); $b-$ интегральная характеристика термоупругого отклика; $c$ - осциллограмма термоэлектрического отклика медных образцов и их интегральные зависимости $(d) .1$ - состояние поставки, 2 - после ИПДК.

трический импульсный отклик на воздействие импульса излучения измерялся на сопротивлении $10 \mathrm{k} \Omega$. Регистрация электрических сигналов осуществлялась широкополосным осциллографом TDS-752C.

Исследования проводились на образцах меди M1 и сплавов алюминия АД1 в состоянии поставки с размером зерна порядка $30-40 \mu \mathrm{m}$ и после интенсивной пластической деформации кручением (ИПДК), которая приводила к измельчению зерна до размеров 0.7-0.9 $\mu \mathrm{m}$. Поверхности образцов диаметром $20 \mathrm{~mm}$ с толщинами порядка $1.5 \mathrm{~mm}$ были отшлифованы и отполированы.

На рис. 4 представлены результаты измерений термоупругого (рис. 4,a) и термоэлектрического (рис. 4,c) отклика медных (M1) образцов в исходном состоянии и после ИПДК. Там же приведены интегральные зависимости экспериментальных кривых, которые для термоупругого отклика (рис. 4, $b$ ) пропорциональны изменению среднего механического импульса в процессе теплопереноса и изменению переноса заряда для термоэлектрического отклика (рис. $4, d$ ).

Термоупругие напряжения и термоэлектрический отклик демонстрируют достаточно сильную зависимость от микроструктуры образцов. Величины фазы растяжения и термоэлектрического импульса значительно меньше в образцах после ИПДК, что определяется сни- жением теплопроводности и электропроводности этих образцов, обусловленное существенным ростом плотности межзеренных границ, т.е. ростом плотности потенциальных барьеров для потока электронов.

Различие интегральных характеристик в большей мере демонстрируют влияние микроструктуры материала на термоупругий и термоэлектрический отклик испытываемого образца. Качественно подобные результаты были получены и при исследовании образцов алюминия АД1.

Известно, что при ударных нагружениях в металлах, в результате пластического течения, происходит перестройка микроструктуры $[25,26]$. В этой связи были проведены исследования чувтвительности параметров термоупругого и термоэлектрического откликов к изменению микрострутуры в результате ударного нагружения длительностью $t_{\text {shock }} \approx 1 \mu \mathrm{s}$ и давлением порядка $1 \mathrm{GPa}$ образца меди М1РО. Из образца диаметром $65 \mathrm{~mm}$ и толщиной $7 \mathrm{~mm}$, нагруженного ударом, были вырезаны два диска диаметром $20 \mathrm{~mm}$ из области удара и периферии образца. Оба диски шлифовались с двух сторон до толщин $h \approx 3 \mathrm{~mm}$ и далее полировались.

Результаты исследований представлены на рис. 5, где показаны термоупругие и термоэлектрические импульсы 

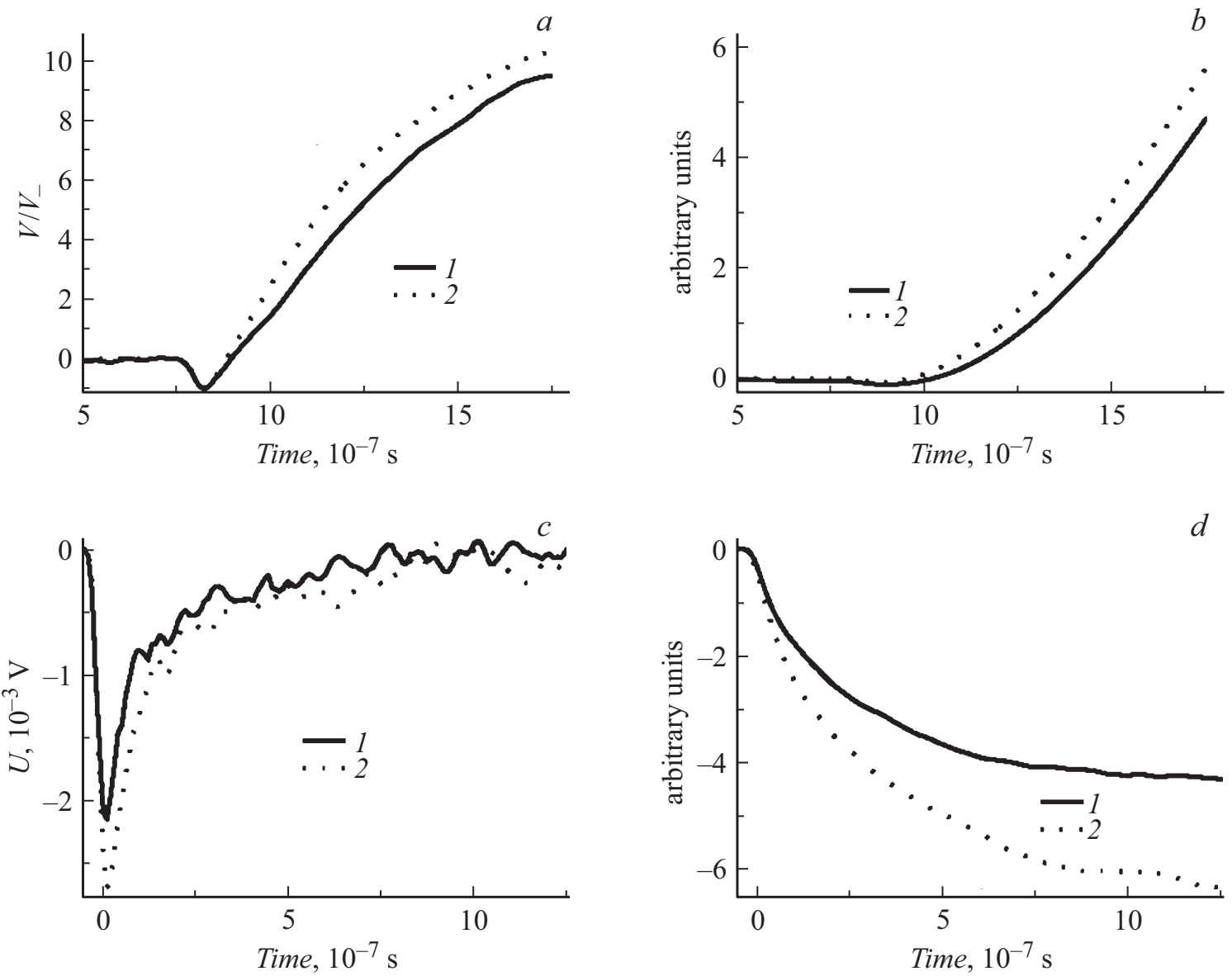

Рис. 5. $a$ - термоупругие импульсы в образцах, вырезанных из периферии (1) и области удара $(2)$; $b-$ их интегральные зависимости; $c$ - термоэлектрические отклики в этих образцах; $d-$ их интегральные зависимости.

в образцах, вырезанных из периферии (1) и области удара (2), а также их интегральные зависимости.

На рис. 5, $a$ приведены нормированные на фазу сжатия импульсы термоупругого отклика в образцах, вырезанных из области удара (сплошная кривая) и из периферийной области (пунктирная кривая).

Оказалось, что в образце из области удара величина фазы растяжения существенно превышает таковую для образца с периферии. То есть, как следует из анализа задачи динамической термоупругости, увеличение фазы растяжения характеризует увеличение теплопроводности и электропроводности материала в области удара. Подтверждением этому служит и возрастание величины термоэлектрического импульса в образце из области ударного нагружения (рис. $5, c$ ).

По-видимому, в результате удара перестройка микроструктуры в области остаточной деформации привела к снижению плотности потенциальных барьеров, возможно, из-за наведенной ударной волной текстуры вдоль направления удара.

Влияние микроструктуры на термоупругий и термоэлектрический отклики исследуемых металлов существеннее проявляется на их интегральных характеристиках.
Дальнейшее развитие этих методик позволит создать высокочувствительный метод неразрушающего контроля конструкционных материалов.

\section{Выводы}

Таким образом, показано, что характер процесса теплопереноса в металлах определяет параметры как термоупругого, так и термоэлектрического откликов металлов на импульсное лазерное воздействие.

Двухстадийный подход для анализа термоупругого и термоэлетрического процессов в металлах при импульсном лазерном воздействии позволил получить адекватное описание экспериментальных результатов.

Результаты экспериментальных исследований термоупругого и термоэлетрического отклика металлов на импульсное лазерное воздействие продемонстрировали значительную зависимость их параметров от микроструктуры, что показывает возможность разработки высокоэффективного метода неразрушающего контроля качества металлов. 


\section{Финансирование работы}

Работа выполнена в рамках проекта РНФ № 15-1900182.

\section{Конфликт интересов}

Авторы заявляют, что у них нет конфликта интересов.

\section{Список литературы}

[1] Tzou D.Y. Macro-to microscale heat transfer: The lagging behavior, In. Taylor \& Francis Washington, DC, 1997.

[2] Соболев С.Л. // УФН. 1991. Т. 161. Вып. 3. С. 5-29.

[3] Карташов Э.М. Аналитические методы в теории теплопроводности твердых тел. М.: Высшая школа, 2001. 550 с.

[4] Qahtani H.Al., Yilbas B.S. // Phusica. B. 2010. P. 3869-3874.

[5] Yuan L., Sun K., Shen Z., Ni X., Lu J. // Intern. J. Thermophysics. 2015. Vol. 36. N 5-6. P. 1057-1065.

[6] Альваро Ф. Карбалло Санчес, Гуревич Ю.Г., Логвинов Г.Н., Дрогобиикий Ю.В., Титов О.Ю. // ФТТ. 1999. Т. 11. Вып. 4. С. 606-611.

[7] Вихор Л. О развитии термоэлектрического материаловедения / Доклад на XIII Международном форум по термоэлектричеству. Киев, 2009.

[8] Абрикосов А.А. Основы теории металлов. М.: Наука, 1987. C. 520.

[9] Блатm Ф. Физика электронной проводимости в твердых телах. М.: Мир, 1971. 470 с.

[10] Воробьев Б.В., Недбай А.И., Судьенков Ю.В., Филиппов Н.М. // Письма в ЖТФ. 1983. Т. 9. Вып. 7. С. 395-399.

[11] Аверьянов Н.Е., Балошин Ю.А., Павлишин И.В., Судьенков Ю.В., Юревич В.И. // ЖТФ. 1987. Т. 57. Вып. 11. C. 2123-2130.

[12] Вовненко Н.В., Зимин Б.А., Судьенков Ю.В. // ЖТФ. 2011. Т. 81. Вып. 6. С. 57-62.

[13] Ашкрофт Н., Мермин Н. Физика твердого тела. М.: Мир, 1979. T. 1.399 c.

[14] Займан Джс. Элетроны и фононы. М.: ИЛ, 1962. 488 с.

[15] Sudenkov Yu.V., Zimin B.A. // Intern. J. Heat and Mass Transfer. 2015. Vol. 85. N 6. P. 781-786.

[16] Зимин Б.А., Судьенков Ю.В. // Письма в ЖТФ. 2012. Т. 3. Вып. 24. С. 26-32.

[17] Даниловская В.И. // Изв. АН СССР. Механика и машиностроение. 1959. № 3. С. 129-132.

[18] Гусев В.Э., Карабутов А.А. Лазерная оптоакустика. М.: Наука, 1991. 304 с.

[19] Лямшев Л.М. Радиационная акустика. М.: Наука, 1996. $302 \mathrm{c}$.

[20] Зимин Б.А., Свентицкая В.Е., Судьенков Ю.В. // Вестн. СПб. ун-та (сер. математика, механика, астрономия). 2018. Т. 5. Вып. 1. С. 131-138.

[21] Рэди Джс. Действие мощного лазерного излучения. М.: Мир, 1974. 468 с.

[22] Анисимов С.И., Имас Я.А., Романов Г.С., Ходыко Ю.В. Действие излучения большой мощности на металлы. М.: Наука, 1970. 272 с.

[23] Ландау Л.Д., Лифшии, Е.М. Электродинамика сплошных сред. М.: Наука, 1982. 621 с.

[24] Кузелев М.В., Рухадзе А.А. Методы теории волн в средах с дисперсией. М.: Физматлит, 2007. 271 с.
[25] Трефилов В.И., Моисеев В.Ф., Печковский Э.П. и др. Деформационное упрочнение и разрушение поликристаллических материалов. Киев: Наук. думка, 1987. 245 с.

[26] Конева Н.А., Козлов Э.В. // Изв. вузов. Физика. 1990. № 2. C. 87-106. 